\title{
The Reciprocal Effect of Crowding and Experiential Stress
}

\author{
Hotwani, Geetu P. ${ }^{1}$ and Tripathi S. K. ${ }^{2}$
}

\begin{abstract}
The exposure to crowding in everyday life leads to stress, frustration, anger and reduced coping abilities. The demands of living and working expose people to different situations irrespective of individual differences. Crowding is a personal, perceived state of mind that may occur owing to environmental realities i.e., high population density (Baron and Richardson, 2004). Crowding refers to the feeling of others being too close versus them actually being too close (Stenstrom, 2010). There are variations in these terms; and, as a matter of fact crowding is subjective and density objective. Researchers place confusion on the two when they do not differentiate them from one another, and yet use them interchangeably (Stokols, 1972). Research shows that crowding gets positive and negative reactions of people. Freedman (1975) states that crowding will increase the normal reaction that individuals have to any situation. Every now and then people cope by withdrawal, going with the flow or getting affected physically or mentally. Lepore, Evans, Irvine and Palsane (1991) found the interactive effects of an enduring environmental stressor with acute social stressors on psychological distress. In India, social hassles in the home showed psychological symptoms only among residents of crowded homes, after statistically adjusting for income. The interaction between social hassles and crowding was replicated in analyses adjusting for prior psychological symptoms, prior social acquaintanceship with house mates, and income. A six-month follow-up study with the American sample showed the same result. In all three analyses of the social hassle-crowding interaction, there was an effect of crowding but no effect of social hassles on psychological symptoms. These findings do suggest that some chronic environmental stressors may increase impact of acute social stressors, and highlight the importance of examining the contextual factors in the stress and health process (Tripathi and Vidya, 2002; Pandey, 1999). The relationship between experiential crowding and stress will be reviewed in this paper and its effects will be explored.
\end{abstract}

Scholar, Department of Psychology, Mother Teresa Women's University,

Kodaikanal, TN, India.

The issue of crowding has received a lot of attention due to the increase in the density of population and the accompanying stress of living in crowded cities. The exposure to crowding leads to stress, frustration, anger and reduced coping abilities. The demands of living and working expose people to different situations irrespective of individual differences. People may cope by withdrawal, going with the flow or they get affected physically or mentally. Crowding has an effect on stress levels and adversely affects physical and psychological health leading to more conflict and deterioration in interpersonal relationships. Crowded households may experience more conflict situations and less support. Individuals may feel suffocated, misunderstood, react in exaggerated ways to situations when they are undergoing stress regularly. Crowding may have an impact on children by adversely affecting their academic performance and stress levels. A host of laboratory and field studies have revealed social withdrawal among crowded children (Aiello, Thompson, \& Baum, 1985). Social support also appears to deteriorate among adult household members as a function of density (Evans \& Lepore, 1993; Evans, Palsane, Lepore, \& Martin, 1989; Lepore, Evans, \& Schneider, 1991). Parents in more crowded homes reported more corporal punishment (Booth \& Edwards, 1976), greater irritability with their children (Gove \& Hughes, 1983), and more quarrelling and fighting among family members (Booth \& Edwards, 1976). Parents in more crowded homes are also more critical and less responsive to their children (Bradley \& Caldwell, 1984; Evans, Maxwell, \& Hart, 1999; Wachs, 1989). Finally, children from crowded versus uncrowded homes reported greater anger and conflict in their families (Saegert, 1982). The theoretical literature on the experience of crowding focuses on the two analytically oriented concepts; an excess of stimulation and a lack of privacy. Desor (1972) defines crowding as "receiving excess of stimulation from social sources". Other investigators who have emphasized stimulus overload in the experience of crowding are Rapport (1972), Galle, Gove and Mcpherson (1972) and Wohlwill \& Carson (1972). A number of theories exist as to why crowding environments possess a great number of factors that hamper the normal functioning of the individuals.Baldassare (1995) reported another model of household crowding. This model raised the argument that objective household overcrowding conditions lead to the subjective experience of crowding, which results in psychological stress. It is the individual stress developed from such crowding experiences that leads to a number of deficiencies in family relations and personal well-being. Altman, while recognizing the importance of stimulus over-load, felt that the concept of privacy is the key to understanding crowding. 
A study was conducted to assess the level of crowding of students in a hostel in Nigeria where space was a major constraint. Many students had to share a single room. This led to physical symptoms like infections, lack of sleep, weakness and urinary infections. In such situations where people of different backgrounds are brought to live under the same roof, many social, psychological and health consequences may arise from such living arrangements. Residential crowding has been linked both with physical illness (Krieger and Higgins, 2002), and with psychosocial distress among both adults and children. Children who live in crowded housing may have poorer cognitive and psychomotor development or they may tend to be more anxious, socially withdrawn, stressed or aggressive (Evans, 2006). Fuller et al (1993) identify two reasons why crowded conditions may be harmful to health: first, the stress associated with crowding may depress the immune system and have other direct health effects; second, overcrowded conditions may facilitate the spread of communicable diseases. The link between experience of crowding and associated poor psychological health had also been documented by Gove, et al (1979). The psychological effects of overcrowding are interlinked with social effects. Overcrowding contributes to psychological frustrations which, in turn affect one's ability to cope with the situation. It has also been noted that people who feel crowded for long periods of time can become psychologically demoralized, depressed and anxious, Lepore (1994). Individuals with experience of crowding often exhibit a pattern of somatic and social reactions in addition to their psychological reactions. Overcrowding is considered a chronic stress which exacerbates other stresses. Baum and Koman (1976) study of the psychological effects of social and spatial density found that people living in high social destiny environments were more likely to become socially withdrawn, while responses to spatial density include aggressive behavior. While social stressors arise from unsatisfactory or negative interpersonal interactions and dependencies, environmental stressors arise from suboptimal conditions in built or natural settings (Evans 1982; Evans and Cohen, 1987). Rook (1990) has suggested that the presence of social stressors may augment the negative effects of other social stressors. These findings suggest that the effect of stress maybe multiplied if there is daily or chronic stress and coping abilities maybe affected or reduced. A cross-sectional study was conducted in male students in India and a longitudinal study of some male and female students in America to check the interactive effects of enduring environmental stressors, daily social stressors on psychological distress. Results showed that individuals who were exposed to daily environmental stressors showed negative effect, distress and compromised psychological health. This kind of stress was present in people who lived in high density conditions, people who lived in low density conditions did not suffer from this issue. The chronic stressor being the crowded condition had affected the adaptive capacities of the highly crowded individuals. There is considerable evidence that low levels of control over the physical environment contributes to psychological distress (Cohen et al; 1986; Evans and Cohen, 1987). Minor social hassles maybe interpreted or viewed negatively by chronically crowded individuals. The joint effect of chronic crowding and social hassles on psychological distress is greater than expected. People who have been affected by chronic crowding may show reduced adaptive capacities if they have been going through continuous stress. Another study of student residential halls in Nigeria by Dolapo Amole brings out the relationship between crowding and stress. It also highlights students coping strategies for dealing with the crowded situation. Student's population within most halls of residence in the country tripled within two decades (Amole, 1997). These increases in population were experienced at every level of social interaction, from the level of the study-bedroom to the whole university. Amole (1997) showed that the social densities within the study bedrooms were officially doubled and unofficially tripled. Amole (1998) and Oruwari (1986) have shown that there is a lack of congruence between what the students desire and the reality of their living experiences. The study examined the responses to the room occupancy in order to determine whether the antecedent condition of perceived crowding truly exists. It identified the types of coping strategies and the relationship between the types of strategies used and the perceived alternatives that the students had. It also examines gender differences in coping styles and the relationship between coping and length of stay.Some other studies (Spencer \& Banerji, 1985; Altman, 1975; Baum \& Paulus, 1987) in housing also indicated that the key psychological variables in shared accommodation and high-density situations are personal space, privacy, and territoriality. In other words, they suggested that user needs in shared or crowded situations are for well-defined strategies to achieve personal territories, desired levels of privacy, and preferred interaction distance. Furthermore, Altman (1975) has shown that the most important psychological concept under which these needs are subsumed is privacy, and the underlying theme is control. He also stated that the failure to achieve desired levels of privacy is shown to result in the experience of crowding stress, which in turn is dealt with through the coping process. Attempting to cope with crowding stress is therefore considered synonymous with attempting to maintain desired levels of privacy and control. A number of social and architectural mechanisms that have been used to maintain privacy and control in residential environments were identified by Altman (1975), Mercer and Benjamin (1980), and Hansen and Altman (1976). Carlisle (1982) showed that more privacy was achieved by locating activity areas behind barriers such as doors, windows, and curtains. In a shared accommodation, Mercer and Benjamin (1980) showed that students would seek to define and protect private territories for themselves within the room even though the 
social and architectural mechanisms for establishing and defining these territories were not specifically addressed. However, in an earlier study, Hansen and Altman (1976) identified decoration as the practice of territorial marking and personalization of one's area within the bedroom. Other strategies were cited by Heilwel (1973). These included the use of auditory screens, headphones, closed doors, and staggered time use. Students also needed more solitude in shared accommodation. The two types of mechanisms people use to achieve desired levels of privacy in crowded situations, according to Altman (1975), are the following: (a) mechanisms that enable people to define territories for self, which may be referred to as control mechanisms and are often expressed physically; and (b) avoidance or withdrawal types of mechanisms, examples of which are time scheduling, avoiding others, and seeking solitude, that are usually socially expressed. Another interesting dimension of the issue of coping lies in the generally preferred coping styles between the sexes. Aiello, Epstein, and Karlin (1977) showed, for example, that males appeared more likely to use avoidance coping strategies. Spencer and Banerji (1985) found that time-sharing and planning one's activities together was a more frequent strategy by females. Mercer and Benjamin (1980) also identified gender differences in the definition of territories. Whereas males maximized personal territories and minimized shared spaces, females thought that shared spaces were more important. Prolonged duration of stay in the hostels also reduced tolerance to crowding stress. These studies show that there is a reciprocal effect between stress and crowding. Being in a crowded environment may cause some adverse reactions which may be unavoidable in many circumstances. The effects maybe increased or reduced by various factors such as mood, stress levels, physical health, coping abilities and general well being of the individual. Sometimes individual coping mechanisms may become impaired or diminished due to excessive stress or unfavourable environmental conditions.

\section{REFERENCES}

[1] Adekunle Anthony Adegoke, (Sep. 2014) Perceived effects of overcrowding on the physical and psychological health of hostel occupants in Nigeria, IOSR Journal Of Humanities And Social Science (IOSR-JHSS) Vol. 19, Issue 9, Ver. VIII (Sep. 2014), PP01-09.

[2] Aiello, J. R.,Thompson, D. E., \& Baum, A. (1985). Children, crowding, and control: Effects of environmental stress on social behavior. In J. F. Wohlwill and W. van Vliet, (Eds.), Habitats for children: The impacts of density. Hillsdale, New Jersey: Lawrence Erlbaum Associates, pp. 97-12

[3] Aiello, J. R.,Epstein, Y. M., \& Karlin, R. A. (1977). Crowding and the role of interpersonal distance preference. Sociometry, 40, 271-282.

[4] Altman, I. (1975). The environment and social behavior: Privacy, personal space, territory and crowding. Pacific Grove, CA: Brooks/Cole.

[5] Altman, I.(1975) The Effects of Crowding and Social Behaviour, Brooks/Cole Publishing Co., California.

[6] Amole,O.O. (1997). An evaluation of students residential facilities in some Nigerian universities.

[7] Obafemi Awolowo University, Ile-Ife, Nigeria.

[8] Amole,O. O. (1998). The experience of dwelling in students residential facilities. In B. Amole

[9] (Ed.), Habitat studies in Nigeria: Some qualitative dimensions (pp. 36-45). Ibadan, Nigeria:

[10] C. I. Shaneson Ltd.

[11] Baldassare, M. (1978). Human Spatial behaviour: Annual Review of Sociology: 4; 29-56

[12] Baldassare, M. (1988) Residential crowding in the United States: A review of the research, Handbook of Housing and the Built Environment in the U.S.

[13] Baldassare, M. (1995). Household crowding and its consequences: Book review Baron, R. ; Mandel, D; Adam; C.; Griffen, L. (1976). Effects of Social Density on University Students. Journal of Personality and Social Psychology. 34;434-446.

[14] Baron, R. M., Mandel, D. R., Adams, C. A.,\& Griffen, L. M. (1976). Effects of social density in

[15] university residential environments. Journal of Personality and Social Psychology, 34, 434-

[16] 446.

[17] Baum, A.,\& Davies, G. (1980). Reducing stress of high density living: An architectural intervention. Journal of Personality and Social Psychology, 38(3), 471-466.

[18] Baum, A., \& Koman, S. (1976). Differential response to anticipated crowding: Psychological

[19] effects of social and spatial density. Journal of Personality and Social Psychology, 34, 526-

[20] 536.

[21] Baum, A., \& Paulus, P. (1987). Crowding. In D. Stokols \& I. Altman (Eds.), Handbook of environmental psychology (Vols. $1 \&$ 2, pp. 533-570). New York: John Wiley.

[22] Baum, A.,\& Valins, S. (1977). Architecture and social behavior: Psychological studies of social

[23] density. Hillsdale, NJ: Lawrence Erlbaum.

[24] Bradley, R., \& Caldwell, B. (1984). The HOME inventory and family demographics. Developmental Psychology, 20, 315-320

[25] Carlisle, S. G. (1982). French homes and French character. Landscape, 26(3), 13-23. 
[26] Cohen, S., Evans, G. W., Stokols, D. \& Krantz, D. S. (1986). Behavior, health, and Environmental Stress. New York: Plenum

[27] D'Atri, D. Psychophysiological responses to crowding. Environment and Behavior. 1975, 7, $237-252$.

[28] Desor, J.A. (1972). Toward a Psychological theory of Crowding. Journal of personality and Social Psychology 21; 79-83.

[29] Evans, G.W. Behavioral and physiological consequences of crowding in humans. Journal of Applied Social Psychology, 1979, 9, 27-46.

[30] Evans, G.W.(2006) Child development and the Physical Environment. Annual review of Psychology, 57: 423-5

[31] Evans, G. W. \& Cohen, S. (1987). Environmental stress. Wilson Centennial Lecture, Human Ecology, University In D. Stokols \& I. Altman, Eds, Handbook of Environ- of Texas, Austin.. New York: Wiley, pp. 571-610

[32] Frankenhaeuser, Dunne \& Lundberg, 1976; Johansson, 1972). Urban Commuting: Crowdedness and Catecholamine Excretion, Journal of human stress 2(3):26-32 - October 1976, DOI: 10.1080/0097840X.1976.9936067

[33] Fuller, T. D., Edwards, J.N., Sermsri, S. and Vorakitphokatorn, S. (1993) Housing, stress and physical well-being: Evidence from Thailand, Social Science Medicine Vol. 36, 11, 1417-1428.

[34] Parental Language and Verbal Responsiveness to Children in Crowded Homes, Gary W. Evans and Lorraine E. Maxwell; Betty Hart, Developmental Psychology 1999, Vol. 35, No. 4, 1020-1023

[35] Galle, O.. Gove, W.R; McPherson J.M. (1972). Population density and Pathology; what are the relationships for man? Science: 176; 23-30.

[36] Gary W. Evans, Stephen J. Lepore, B. R. Shejwal, and M. N. Palsane (1998) Chronic Residential Crowding and Children's Well-Being: An Ecological Perspective, Child Development, December 1998, Vol. 69, Pages 1514 - 1523.

[37] Gove, W.R.; Hughes,. M. and Galle, O.R (1979). Overcrowding in the home: An empirical investigation of its possible pathological consequences. American Sociological Review Vol. 44 (Feb), 59-80.

[38] Hansen,W.B.,\& Altman, I. (1976). Decorating personal places: A descriptive analysis. Environment and Behavior, 8(4), 491-504.

[39] Heilwel, M. (1973). The influence of dormitory architecture on resident behavior. Environment

[40] and Behavior, 5, 815-830.

[41] Krieger, J and Higgins, D.L.(2002) Housing and Health: Time again for public health action. American journal of Public Health,92(5): 758-68

[42] Lepore, Stephen J; Gary W. Evans and Margaret L. Schneider. 1991. " The Dynamic role of Social Support in the Link Between Chronic Stress and Psychological Distress. " Journal of Personality and Social Psychology.

[43] Lepore, S. J. (1994). Crowding: effects on health and behavior.In V. S. Ramachandran (Ed.), Encyclopedia of Human Behavior, Vol. 2. San Diego, CA: Academic Press, pp. 43-51.

[44] Mercer, W. G.,\& Benjamin, M. L. (1980). Spatial behavior of university undergraduates in double occupancy residence rooms: An inventory of effects. Journal of Applied Social Psychology, 10(1), 32-44. 218 ENVIRONMENT AND BEHAVIOR / March 2005

[45] Rook, Karen S. 1990, “ Parallels in the Study of Social Support and Social Strain ". Journal of Social and Clinical Psychology 9: 118 - 32.

[46] Saegert, S. (1982). Environment and children's mental health: Residential density and low income children. In A. Baum \& J. E. Singer (Eds.), Handbook of psychology and health (pp. 247-271). Hillsdale, NJ: Erlbaum

[47] Spencer, C., \& Banerji, N. (1985). Strategies for sharing student accommodation. Architecture and Behavior, 2, 123-135.

[48] Stephen J. Lepore ,Gary W. Evans, Irvine M. N. Palsane (1991) Social Hassles and Psychological Health in the Context of Chronic Crowding, Journal of Health and Social Behavior 1991, Vol. 32 (December): 357-367

[49] Stokols, D.(1972). On the distinction between density and crowding: Some implications for future research. Psychological Review. 79(3), 275-277.

[50] Wachs, T. D. (1989). The nature of the physical microenvironment: An expanded classification system. Merrill-Palmer Quarterly, 35, 399-419.

[51] Wohlwill, F., and Carson, D.H.(1972) Environment and the social sciences: Perspectives and applications: Washington D.C. American Psychological Association. 